\title{
Effect of Variable Temperature on Infection Severity of Podosphaera macularis on Hops
}

\author{
Walter F. Mahaffee, William W. Turechek, and Cynthia M. Ocamb
}

First author: U.S. Department of Agriculture-Agriculture Research Service-Horticulture Crops Research Laboratory, 3420 NW Orchard Ave., Corvallis, OR 97330; second author: Cornell University, NYSAES, Department of Plant Pathology, Barton Laboratory, Geneva, NY 14456; and third author: Oregon State University, Department of Botany and Plant Pathology, Cordley Hall, Corvallis, OR 97331. Accepted for publication 28 July 2003

\section{ABSTRACT}

Mahaffee, W. F., Turechek, W. W., and Ocamb, C. M. 2003. Effect of variable temperature on infection severity of Podosphaera macularis on hops. Phytopathology 93:1587-1592.

The effect of variable temperature on the infection severity of $\mathrm{Po}$ dosphaera macularis was investigated. Potted 'Symphony' hop plants were inoculated and exposed to different temperature regimes that included supraconducive temperatures $\left(30\right.$ to $42^{\circ} \mathrm{C}$ ) for varying periods of time (2 to $9 \mathrm{~h}$ ). Infection severity (lesions per $\mathrm{cm}^{2}$ of leaf area) was calculated 7 to 10 days after inoculation. Immediately exposing inoculated plants to $30^{\circ} \mathrm{C}$ for as little as $2 \mathrm{~h}$ significantly $(P \leq 0.05)$ reduced infection severity compared with exposure at a constant $18^{\circ} \mathrm{C}$. However, exposure of inoculated plants to optimal conditions for 24 or $48 \mathrm{~h}$ prior to exposure to supraconducive conditions reduced this effect for plants exposed to 30 , 33 , or $36^{\circ} \mathrm{C}$. Exposure to 39 or $42^{\circ} \mathrm{C}$ for 2 or more hours resulted in in- fection frequencies not significantly different from that of the uninoculated control regardless of prior exposure to favorable conditions. Exposure to simulated field temperatures programmed into growth chambers indicated that inoculation at 1700 or $2100 \mathrm{~h}$ resulted in significantly more disease than did inoculation at 0900 or $1300 \mathrm{~h}$. Plants exposed to supraconducive or simulated field temperatures for 7 days prior to inoculation developed significantly lower disease severity than did plants maintained at $18^{\circ} \mathrm{C}$ for 7 days. The magnitude, length, and time of exposure to supraconducive temperatures in relation to time of inoculation plays an important role in the development of hop powdery mildew, and rules addressing these variables could be a useful addition to disease risk assessment models.

Additional keywords: Humulus lupulus, Sphaerotheca humuli, Sphaerotheca macularis.
Hop powdery mildew, caused by Podosphaera macularis Braun \& Takamatus (formerly Sphaerotheca macularis (Wallr.:Fr.) Lind syn. S. humuli (DC.) Burrill), is the most economically important disease of hops (Humulus lupulus L.) worldwide (15). The disease has been a long-time problem in European hop production and is arguably the leading threat to hop production in countries where the pathogen is not indigenous. In 1997, P. macularis spread to all hop-growing regions in North America and Europe (15). Losses associated with the disease include reduced yield due to aborted flowers and cones, a decrease in plant vigor, diminished cone quality, and increased fungicide usage (14). In the Pacific Northwest, losses due to these factors approached \$30 million in 1999 and 2000 , or about $15 \%$ of their total crop revenue (Ann George, administrator, U.S. Hop Industry Plant Protection Committee, personal communication). Despite the worldwide importance of this disease, there is a limited understanding of its epidemiology and etiology. This limited understanding has hindered development of sound management of hop powdery mildew in the Pacific Northwest since its introduction in 1997.

In previous work, we examined the effects of constant temperature and leaf age on disease development (22). Disease developed in the range of 12 to $27^{\circ} \mathrm{C}$, and no infection occurred at a constant temperature of $30^{\circ} \mathrm{C}$. The optimal temperature for infection, growth, and sporulation of $P$. macularis was $18^{\circ} \mathrm{C}$. Leaves were

Corresponding author: W. F. Mahaffee

E-mail address: mahaffew@science.oregonstate.edu

Publication no. P-2003-1016-01R

This article is in the public domain and not copyrightable. It may be freely reprinted with customary crediting of the source. The American Phytopathological Society, 2003. susceptible to infection for nearly 2 weeks, but the degree of susceptibility declined steadily with increasing leaf age.

The effects of constant temperature on the ability of various species within the family Erysiphaceae to cause disease have been examined by numerous researchers $(3,4,22,23,25)$. Yet, there have been only a few investigations on the effects of variable temperature on disease development $(18,23,29)$. In the Pacific Northwest, environmental conditions from June through September fluctuate between inhibitory temperatures (supraconducive) during the day and conducive conditions at night (22). It is common for temperatures to reach daytime highs of 35 to $40^{\circ} \mathrm{C}$ with nighttime lows of 15 to $20^{\circ} \mathrm{C}$ in both the Yakima and Willamette Valleys of Washington and Oregon, where hops are produced. To understand fully the effects of temperature on the development of powdery mildew, it is necessary to examine how variable temperature affects disease development. Of particular interest is how infection is impacted when conidia are exposed to periods of supraconducive (i.e., $\geq 30^{\circ} \mathrm{C}$ ) temperatures preceded or followed by conducive conditions. This knowledge will increase our ability to develop effective management programs for $P$. macularis in the Pacific Northwest, including a hop powdery mildew forecaster.

The objective of this investigation was to assess the effects of variable temperature on the infection severity of $P$. macularis. First, the effects of immediate and delayed exposure to supraconducive temperatures were examined. Second, programmable growth chambers were used to simulate field conditions for a single 24-h period, and hop plants were introduced at various points representing times of potential conidial spread. Lastly, the effect of temperature on the susceptibility of the host was investigated based on observations made while investigating the first two objectives. It was observed that exposure to elevated temperatures in growth chambers resulted in reduced leaf size compared with that 
of inoculated controls, and the susceptibility of greenhouse-grown plants changed over the course of the year.

\section{MATERIALS AND METHODS}

Plant maintenance. Clonal plants of the highly susceptible variety Symphony (John I. Haas, Inc., Yakima, WA) were produced from greenwood cuttings (6), planted in 1-liter pots with Sunshine Mix \#1 (SunGro Horticulture, Bellevue, WA), and grown under greenhouse conditions $\left(15\right.$ to $\left.26^{\circ} \mathrm{C}\right)$ with at least a 15 -h photoperiod. Plants were watered as needed and supplied at watering with Champion 17-17-17 fertilizer with micronutrients (McConkey's, Portland, OR). Plants were maintained powdery mildewfree by vaporizing sulfur in the house each night for $4 \mathrm{~h}$.

Inoculation procedure. A field population of $P$. macularis was used in all experiments. The population consisted of several singleconidial-chain isolates of $P$. macularis obtained from Oregon hop yards. The isolates were maintained in growth chambers through successive transfers on potted 'Symphony' plants incubated at $13^{\circ} \mathrm{C}$ with a $15-\mathrm{h}$ daylength $\left(\sim 300 \mu \mathrm{mol} / \mathrm{m}^{2} / \mathrm{s}\right)$.

Inoculum was prepared by collecting infected hop leaves from the growth chamber and washing conidia from the leaves with a $0.005 \%$ ( vol/ vol) solution of Tween 20 and ultra-pure water (Nanopure with organic-free cartridge kit [Barnstead, Dubuque, IA]). Plants were inoculated with a spore suspension of 20,000 conidia per $\mathrm{ml}$ until just before runoff by using a handheld atomizer (Nalgene, Rochester, NY). Spore suspensions allowed more precise and repeatable deposition of conidia on leaves of a large number of plants than did a settling tower, in which overlapping leaves resulted in large areas of uninoculated leaf surface (W. F. Mahaffee, unpublished data). Leaves were air-dried within $1 \mathrm{~h}$ of the preparation of the conidial suspension to prevent lysis of conidia and then placed into growth chambers with a 15-h daylength set at various temperatures.

Disease assessment. Infection severity was used as a measure of disease severity. Infection severity was calculated by counting the number of lesions per leaf 7 to 10 days after inoculation and
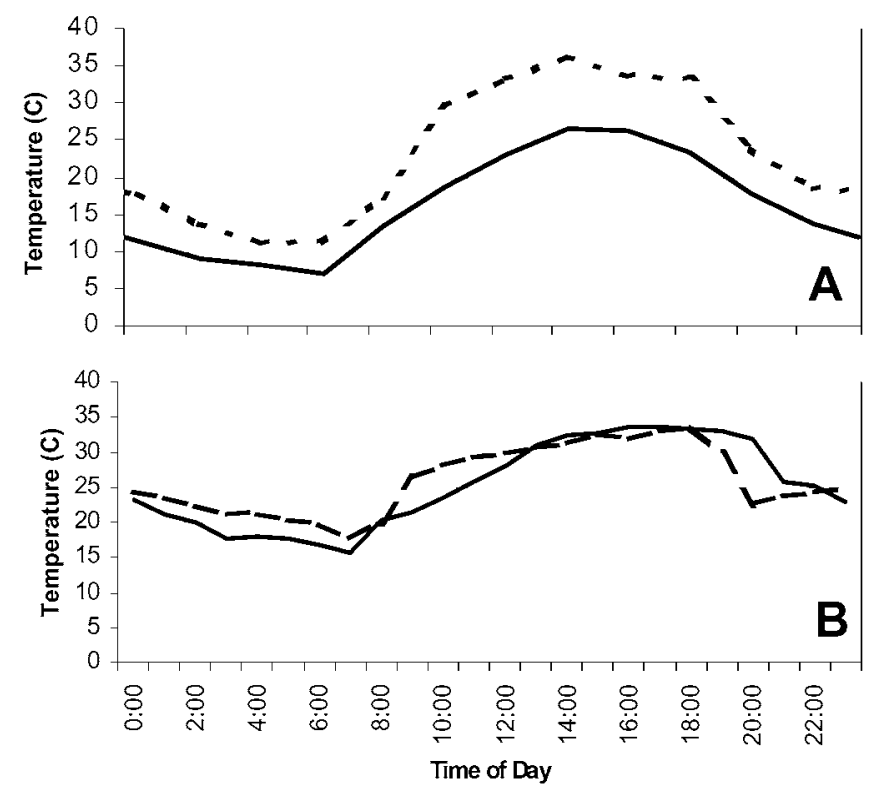

Fig. 1. Temperature regimes for experiments on the effect of fluctuating temperatures on the infection severity of Podosphaera macularis on hops. A, Averaged temperature data from 13 hop yards in the Yakima Valley, WA, for 8 May 2000 (solid line) and 9 August 2000 (dashed line). These days were randomly chosen from their respective months. B, Hourly observations from a hop yard in Mabton, WA, for 26 May 2001 (solid line) and 2 July 2001 (dashed line). These days were chosen because they represented the first day of two different heat waves in the region. dividing this value by leaf area $\left(\mathrm{cm}^{2}\right)$. The effect of ontogenetic resistance (22) was reduced by using only the first two nodes with fully unfurled leaves (two leaves at each node) at the time of inoculation to measure infection severity. Leaf area was determined by using the average of two measurements obtained with a Li-Cor LI-3000 leaf area meter (Li-Cor Inc., Lincoln, NE). Infection severity was then averaged across the leaves for each plant. In previous work, there was a correlation between infection severity and lesion size (a measure of the resistance to colonization) (22); therefore, measuring infection severity also provided qualitative information on lesion size.

Experimental design. Unless stated otherwise, all experiments were arranged in a split-plot design with various temperature treatments serving as the whole-plot factor (defined individually for each experiment below) and pre-exposure time, exposure time, or both serving as the subplot factors. Replication in time served as the blocking factor. Three replications were done for each experiment, except where indicated. Noninoculated plants were placed at $18^{\circ} \mathrm{C}$ to determine ambient levels of infection and served as the noninoculated control. Temperatures were randomly assigned to growth chambers for each replication, and two to four plants were examined for each factor combination and control treatment (subsamples). The mean infection severity from the two to four plants was calculated for each replication and used in the analysis. Three-way analysis of variance (ANOVA) was conducted by using the GLM procedure in SAS (SAS Institute, Cary, NC). The factors were block, main plot, and subplots. Comparisons among factor means were done by using Fisher's protected least significant difference test $(P=0.05)$.

In selected experiments, regression analysis was performed to quantify the effect of temperature and immediate or delayed exposure time on infection severity. The mean infection severity over all replications for the factor combinations in question was calculated (5). The means were square-root transformed and regression analyses of all subsets were used to select the best combination of the dependent variables temperature, exposure time, and various transformations of these variables. Residual plots, influence diagnostics, Mallow's $C_{p}$ statistic, a normal probability plot, and common sense were used in the selection of an appropriate model.

Effects of variable temperature on infection severity. In the following experiments, two plants (subsamples) were inoculated for each combination of factors, and uninoculated controls were placed in each chamber and monitored for disease. Temperature in each chamber was monitored with a HOBO pro Series RH/Temp data logger (Onset Computer Corp., Bourne, MA).

Immediate exposure to supraconducive temperatures. This experiment was designed to determine the time of exposure at supraconducive temperatures necessary to inhibit disease development. Plants were inoculated as described above and exposed to temperatures of $30,33,36,39$, or $42^{\circ} \mathrm{C}$ (main-plot factor) for $0,3,6$, or $9 \mathrm{~h}$ (subplot factor) and then incubated at the optimal temperature of $18^{\circ} \mathrm{C}$ for 7 to 10 days. These supraconducive temperatures were chosen based upon temperatures observed at $1.8 \mathrm{~m}$ above ground level in hop yards in 1999. Four replications were conducted.

Delayed exposure to supraconducive temperatures. Plants were inoculated and placed at $18^{\circ} \mathrm{C}$ for $0,8,24$, or $48 \mathrm{~h}$ (subplot), moved to $30,33,36,39$, or $42^{\circ} \mathrm{C}$ (main plot) for $6 \mathrm{~h}$, and then returned to $18^{\circ} \mathrm{C}$ for 7 days. This experiment differs from the first in that plants were exposed first to conducive conditions, with the hypothesis that infection and subsequent disease development would be affected less by supraconducive temperatures after incubation under conducive conditions. Three replications were conducted.

A second experiment was conducted to examine in more detail the effects of delayed exposure times of $<8 \mathrm{~h}$. The main plot was exposure temperature, with subplots being combinations of preexposure time and exposure time. Pre-exposure time consisted of exposing inoculated plants to $18^{\circ} \mathrm{C}$ for 3,5 , or $8 \mathrm{~h}$ (subplot) prior 
to exposure to supraconducive temperatures of $30,33,36,39$, or $42^{\circ} \mathrm{C}$ (main plot) for 2,4 , or $6 \mathrm{~h}$ (sub-subplot). After completing exposure to supraconducive temperatures, plants were returned to $18^{\circ} \mathrm{C}$ for 7 days to allow disease to develop. For example, one individual treatment consisted of placing two inoculated plants at $18^{\circ} \mathrm{C}$ for $5 \mathrm{~h}$, exposing them to $36^{\circ} \mathrm{C}$ for $4 \mathrm{~h}$, and then incubating them at $18^{\circ} \mathrm{C}$ for 7 days. A control consisting of inoculated plants placed at $18^{\circ} \mathrm{C}$ for the duration of the experiment was used as a reference. Additional treatments consisted of noninoculated controls. Two replications were conducted.

Exposure to simulated field temperatures and effect of time of inoculation. Plants were inoculated and then placed into programmable growth chambers (PGR15 with a CMP4030 controller; Convrion, Inc., Winnipeg, Manitoba, Canada) with temperature regimes representing 8 May 2000, 9 August 2000 (Fig. 1A), or a constant $18^{\circ} \mathrm{C}$ (main plot). Temperature data used to program the chamber was originally collected from 13 hop yards in the Yakima Valley, WA, with HOBO Pro data loggers (1.8 $\mathrm{m}$ above the soil) programmed to record air temperature data every $15 \mathrm{~min}$. The 15-min-interval data were averaged over the 13 hop yards, and this was averaged in 2-h intervals (e.g., temperature value for $0600 \mathrm{~h}$ represents the average of temperature readings from 0515 to $0700 \mathrm{~h}$ for all 13 field observations). The chambers were programmed to ramp between data points to simulate diurnal temperature fluctuations observed in the field. These days were randomly chosen from their respective months.

Three plants per temperature regime were inoculated at 0900 , 1300,1700 , or $2100 \mathrm{~h}$ (time of inoculation); placed in a growth chamber; exposed to that temperature regime for $24 \mathrm{~h}$; and then moved to $18^{\circ} \mathrm{C}$ for 9 days or left at that temperature regime for 10 days. The main plot was temperature regime with time of inoculation serving as the subplot. Three replications were conducted.

Effect of temperature on host susceptibility. Effect of constant temperatures. Growth chambers were maintained at 18, 24, $26,28,30$, and $32^{\circ} \mathrm{C}$ and six plants were placed in each chamber. After 7 days, the plants were inoculated with a powdery mildew spore suspensions as described above and then incubated at $18^{\circ} \mathrm{C}$. Plants were assessed for disease 10 days after inoculation. Three replications were conducted.

Exposure to simulated field temperatures. Nine plants were placed in growth chambers programmed with hourly data collected from a hop yard in Mabton, WA, from 26 May 2001, 2 July 2001 (Fig. 1B), or at a constant $18^{\circ} \mathrm{C}$ (main plot). These particular days were chosen because they were representative of two different heat waves in the Yakima Valley. After 7 days (the time for two leaves to become fully expanded), plants were inoculated at $1700 \mathrm{~h}$ and placed at $18^{\circ} \mathrm{C}$ for 10 days. In addition, uninoculated controls were left at each temperature regime for the duration of the experiment. Two replications of this experiment were conducted.

TABLE 1. Effect of exposure to supraconducive temperatures ${ }^{\mathrm{w}}$ on the infection severity ${ }^{\mathrm{x}}$ of Podosphaera macularis on hops immediately after inoculation

\begin{tabular}{llccccc}
\hline $\begin{array}{l}\text { Exposure time } \\
\text { (h) }\end{array}$ & \multicolumn{4}{c}{ Exposure temperature $\left({ }^{\circ} \mathrm{C}\right)$} & $\begin{array}{c}\text { Exposure time } \\
\text { mean }^{\mathrm{y}}\end{array}$ \\
\cline { 2 - 5 } & 30 & 33 & 36 & 39 & 42 & 2.51 \\
0 & 2.50 & 2.33 & 2.55 & 2.56 & 2.63 & 0.57 \\
3 & 1.34 & 1.09 & 0.36 & 0.005 & 0.001 & 0.26 \\
6 & 1.05 & 0.21 & 0.007 & 0.001 & 0 & 0.21 \\
9 & 0.7 & 0.32 & 0.002 & 0 & 0 &
\end{tabular}

Exposure tem-

$\begin{array}{llllll}\text { perature mean }^{\mathrm{z}} & 1.41 & 0.9 & 0.73 & 0.67 & 0.65\end{array}$

${ }^{w}$ Plants were inoculated with a conidial suspension, air-dried, incubated at temperatures and time periods shown, and then incubated at $18^{\circ} \mathrm{C}$ for 7 days.

${ }^{x}$ Mean infection severity (number of lesions per $\mathrm{cm}^{2}$ of leaf area) of four replications in time.

y Mean infection severity at said exposure time across all exposure temperatures.

${ }^{\mathrm{z}}$ Mean infection severity at said exposure temperature across all exposure times.

\section{RESULTS}

Effects of variable temperature on infection severity. Immediate exposure to supraconducive temperatures. The quantitative factors temperature (T) and exposure time (ET) had a significant effect on the infection severity (IS) according to ANOVA. Increases both in temperature above $30^{\circ} \mathrm{C}$ and in exposure time to supraconducive temperatures for $>3 \mathrm{~h}$ resulted in a significant decrease in infection severity. There was no significant exposure time $\times$ temperature interaction $(P=0.55)$; the means for each factor are presented (Table 1). Regression analysis was used to describe the relationship between temperature and exposure time. The best-fitting regression equation was (Fig. 2A) $\mathrm{IS}^{1 / 2}=1.59-$ $(0.870 \times \mathrm{ET})+\left(3.00 \times \mathrm{ET}^{1 / 2}\right)+(0.0275 \times \mathrm{T} \times \mathrm{ET})-(0.106 \times \mathrm{T} \times$ $\left.\mathrm{ET}^{1 / 2}\right)\left(R^{2}=94.5 \%\right)$.

Delayed exposure to supraconducive temperatures. The quantitative factors temperature (T) and delayed exposure time (DET) had a significant effect on the infection severity (IS) according to ANOVA. Infection severity increased proportionally with the delay of exposure to supraconducive temperatures after exposure to $18^{\circ} \mathrm{C}$ (Table 2). Infection severity decreased as temperature increased from 30 to $42^{\circ} \mathrm{C}$. There was no significant interaction between temperature and delayed exposure time $(P=0.36)$. Regression analysis was used to describe the relationship between infection
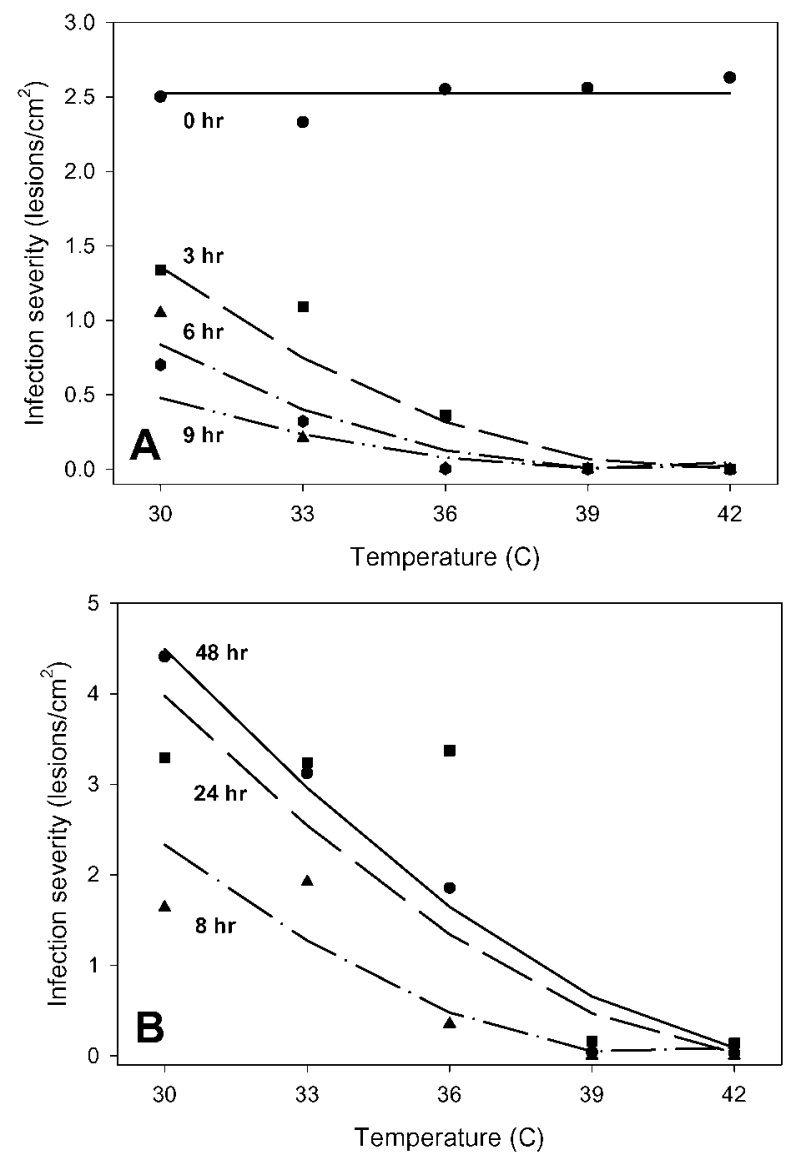

Fig. 2. A, Relationship between infection severity of hop powdery mildew and temperature after $0(\bullet), 3(\boldsymbol{\nabla}), 6(\boldsymbol{\Delta})$, or $9 \mathrm{~h}(\boldsymbol{\bullet})$ of exposure to supraconducive temperatures immediately following inoculation. Plants were held at $18^{\circ} \mathrm{C}$ after exposure to allow disease to develop. Symbols represent mean infection severity over three replications. The lines represent the best fit according to multiple regression analysis. B, Relationship between infection severity of hop powdery mildew and temperature after $6 \mathrm{~h}$ of exposure to 30 , $33,36,39$, or $42^{\circ} \mathrm{C}$ at $8(\boldsymbol{\Delta}), 24(\bullet)$, or $48 \mathrm{~h}(\boldsymbol{\square})$ after inoculation. Plants were held at $18^{\circ} \mathrm{C}$ prior to and after exposure to supraconducive temperatures to allow disease to develop. Symbols represent mean infection severity over three replications. The lines represent the best fit according to multiple regression analysis. 
severity, temperature, and delayed exposure time. The best-fitting regression equation was (Fig. $2 \mathrm{~B}) \mathrm{IS}^{1 / 2}=2.23-\left(0.0021 \times \mathrm{T}^{2}\right)-$ $(0.0401 \times \mathrm{DET})+\left(0.535 \times \mathrm{DET}^{1 / 2}\right)\left(R^{2}=82.3 \%\right)$.

No infections were observed on plants exposed to 39 or $42^{\circ} \mathrm{C}$ for $8 \mathrm{~h}$ after inoculation, while several small colonies were observed on the youngest leaves (i.e., first node) at the time of rating on plants exposed to 39 and $42^{\circ} \mathrm{C}$ for 24 and $48 \mathrm{~h}$ after inoculation. There was no significant exposure time $\times$ temperature interaction $(P=0.55)$; thus, means for each factor are presented (Table 2). A $75 \%$ reduction in infection severity was observed with as little as $3 \mathrm{~h}$ of exposure to supraconducive temperatures. Similarly, a $90 \%$ reduction in infection severity was obtained with 6- and 9-h exposure periods. Exposure to temperatures of 39 and $42^{\circ} \mathrm{C}$ resulted in an infection severity not significantly different from that of the untreated control. Infection severity at 36,39 , or $42^{\circ} \mathrm{C}$ was significantly less than that at $30^{\circ} \mathrm{C}$.

In separate three-factor experiments, in which pre-exposure time at $18^{\circ} \mathrm{C}$ as well as exposure time to conducive and supraconducive temperatures were varied, there were no significant interactions $(P>0.35)$ among any of the main effects. For the factor of exposure temperature, all treatments were significantly different $(P=0.003)$ from the inoculated control (Fig. 3A). Infection severity decreased with increasing exposure temperature, with the exception that no difference between exposure at 30 and $33^{\circ} \mathrm{C}$ was observed. There was no effect of exposure time, but there was a trend $(P=0.08)$ of a reduction in infection severity as the length of exposure to supraconducive temperatures increased (Fig. 3B). Unexpectedly, there was a significant effect $(P<0.0001)$ of preexposure time at $18^{\circ} \mathrm{C}$. The 5 -h pre-exposure treatment at $18^{\circ} \mathrm{C}$ prior to exposure to supraconducive temperatures resulted in significantly higher disease severity than that with 3- and 8-h preexposure treatments (Fig. 3C).

Exposure to simulated field temperatures and effect of time of inoculation. The main effects of temperature regime $(P<0.0001)$ and inoculation time $(P=0.0003)$ were significant, but their interaction term was not $(P=0.52)$. All temperature treatments were significantly different from each other. Both fluctuating temperature regimes resulted in significantly lower infection frequencies than that with the optimal $18^{\circ} \mathrm{C}$. Inoculations performed at $1300 \mathrm{~h}$ resulted in significantly lower infection frequencies than did inoculations performed at either 0900 or $1700 \mathrm{~h}$ (Table 3). Inoculations at $1700 \mathrm{~h}$ resulted in infection frequencies significantly greater $(P=0.05)$ than those at 0900 and $1300 \mathrm{~h}$.

Effect of temperature on host susceptibility. Effect of constant temperature. Only exposure of plants to $32^{\circ} \mathrm{C}$ prior to inoculation resulted in a significant $(P<0.0001)$ reduction in infection severity compared with that of the inoculated control (Fig. 4).

TABLE 2. Effect of exposure to supraconducive temperatures ${ }^{\mathrm{w}}$ on the infection severity ${ }^{\mathrm{x}}$ of Podosphaera macularis on hops after pre-exposure under optimal conditions

\begin{tabular}{lccccccc}
\hline $\begin{array}{l}\text { Pre-exposure } \\
\text { time (h) }\end{array}$ & 18 & 30 & 33 & 36 & 39 & 42 & $\begin{array}{c}\text { Pre-exposure } \\
\text { time mean }\end{array}$ \\
\cline { 2 - 7 } & 4.16 & 1.64 & 1.92 & 0.35 & 0 & 0 & 1.34 \\
8 & 4.27 & 4.41 & 3.26 & 1.85 & 0.04 & 0.003 & 2.29 \\
48 & 4.33 & 3.28 & 3.24 & 3.37 & 0.16 & 0.14 & 2.42 \\
$\begin{array}{l}\text { Exposure tem- } \\
\text { perature mean }\end{array}$ & 4.25 & 3.12 & 2.76 & 1.86 & 0.07 & 0.05 & \\
\hline
\end{tabular}

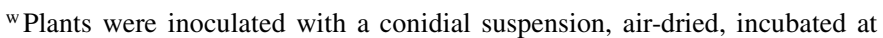
$18^{\circ} \mathrm{C}$ for 8,24 , or $48 \mathrm{~h}$; incubated at $18,30,33,36,39$, or $42^{\circ} \mathrm{C}$ for $6 \mathrm{~h}$; and then incubated at $18^{\circ} \mathrm{C}$ for 7 to 10 days.

${ }^{x}$ Mean infection severity (number of lesions per $\mathrm{cm}^{2}$ of leaf area) of four replications in time.

${ }^{y}$ Mean infection severity at said pre-exposure time across all exposure temperatures.

${ }^{\mathrm{z}}$ Mean infection severity at said exposure temperature across all pre-exposure times.
There was a trend $(P=0.086)$ toward decreased disease severity for exposure to temperatures $\geq 24^{\circ} \mathrm{C}$.

Exposure to simulated field temperatures. Both the 26 May 2001 and 2 July 2001 treatments resulted in significantly lower $(P<$ $0.0001)$ infection frequencies that that under optimal conditions (Fig. 5).

\section{DISCUSSION}

Infection severity of $P$. macularis on hops is highly sensitive to exposure to supraconducive temperatures. Exposure to $30^{\circ} \mathrm{C}$ for as
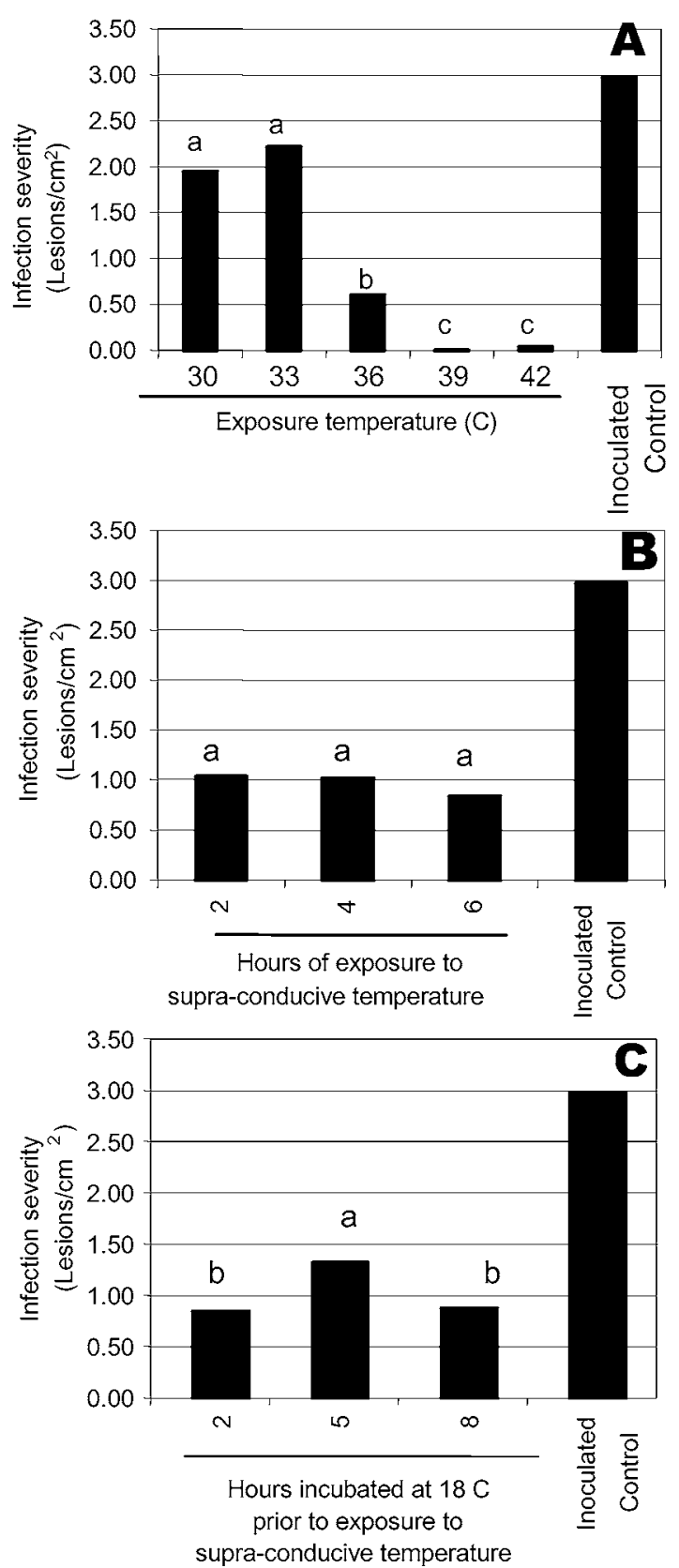

Fig. 3. Effect of exposure periods of Podosphaera macularis on hops to conducive or supraconducive temperatures on infection severity. There were no significant interactions among the main factors. A, Main effect of supraconducive temperatures. B, Main effect of exposure time to supraconducive temperatures. C, Effect of incubation at $18^{\circ} \mathrm{C}$ prior to exposure to supraconducive temperatures. Controls consisted of inoculated plants exposed to a constant $18^{\circ} \mathrm{C}$. Means followed by the same letter are not significantly different at $P=0.05$ using Fisher's protected least significant difference test. All treatments were significantly different from inoculated controls as indicated by Dunnett's test $(P=0.05)$. 
little as $2 \mathrm{~h}$ at the time of inoculation can reduce infection severity by $50 \%$ or more, and exposure to extreme temperatures $\left(\geq 39^{\circ} \mathrm{C}\right)$, which frequently occur in Pacific Northwest hop yards, appears to cause colony death. However, periods of favorable temperatures prior to exposure to supraconducive temperatures reduce this effect. Additionally, exposure to supraconducive temperatures reduced host susceptibility.

The effects of supraconducive temperatures are fairly consistent among experiments; as the length of exposure to supraconducive temperatures increased, infection severity decreased, regardless of timing. The exception was the decreased susceptibility of $P$. $\mathrm{macu}$ laris to supraconducive temperatures after a 5 -h pre-exposure time at $18^{\circ} \mathrm{C}$ (Fig. 3C). This decrease could be related to changes in sensitivity to temperature during appressorium formation. Appressorium formation of $P$. macularis on strawberry occurs $5 \mathrm{~h}$ after spore deposition (18). Quin and Powell (19) observed a similar response for Oidium begoniae on detached leaves with brief exposures to $29^{\circ} \mathrm{C}$. Treatment for 4 -h periods during the first $24 \mathrm{~h}$ after germination only resulted in a reduction in infection severity for the periods 0 to $4 \mathrm{~h}, 8$ to $16 \mathrm{~h}$, and 16 to $24 \mathrm{~h}$ after infection, corresponding to attachment ( 0 to $4 \mathrm{~h}$ ) and penetration and haustorium formation ( 8 to $16 \mathrm{~h}$ and 16 to $24 \mathrm{~h}$, respectively). The $4-$ to 8-h interval corresponded to appressorium formation. Quin and Powell (19) also observed that treatment of whole plants at 28, 32, and $40^{\circ} \mathrm{C}$ for 14,3 , and 2 days, respectively, resulted in eradication of established infections.

$\mathrm{Xu}$ and colleagues $(23,24,26)$ observed that exposure to fluctuating temperatures, particularly when temperatures reached supraconducive levels, increased the latent and incubation periods of $P$. pannosa and $P$. leucotricha on rose and apple, respectively. In the experiments presented here, an increase in the latent period was not noted (data not shown). Regardless of the temperature treatment, colonies were visible within 4 to 6 days after inoculation, and no colonies were ever observed on the uninoculated controls that remained in the chambers programmed with supraconducive temperatures. Only small pinpoint colonies developed on plants exposed to supraconducive temperatures for $>24 \mathrm{~h}$ or placed in simulated field temperature regimes (data not shown). Turechek et al. (22) observed a similar response for P. macularis under constant supraconducive temperatures. This difference in latent periods observed by $\mathrm{Xu}$ (23) could be because of spread from other sources, since the experimental conditions used did not appear to account for the potential of secondary spread or exposure to air-

TABLE 3. Effect of simulated field temperature fluctuations and inoculation time on the infection severity ${ }^{\mathrm{v}}$ of Podosphaera macularis on hops

\begin{tabular}{lcccc}
\hline \multirow{2}{*}{$\begin{array}{l}\text { Time of } \\
\text { inoculation }^{\mathrm{w}}\end{array}$} & \multicolumn{3}{c}{ Temperature regime $^{\mathrm{x}}$} & \multirow{2}{*}{$\begin{array}{c}\text { Inoculation } \\
\text { time mean }^{\mathrm{y}}\end{array}$} \\
\cline { 2 - 5 } & Constant $18^{\circ} \mathrm{C}$ & 8 May 2000 & 9 August 2000 & $0.74 \mathrm{~b}$ \\
$0900 \mathrm{~h}$ & 1.13 & 0.94 & 0.16 & $0.28 \mathrm{a}$ \\
$1300 \mathrm{~h}$ & 0.51 & 0.33 & 0.006 & $1.15 \mathrm{c}$ \\
$1700 \mathrm{~h}$ & 1.69 & 1.26 & 0.53 & $0.87 \mathrm{bc}$ \\
$2100 \mathrm{~h}$ & 1.49 & 0.76 & 0.43 & \\
$\begin{array}{l}\text { Temperature } \\
\text { regime mean }\end{array}$ & $1.2 \mathrm{a}$ & $0.82 \mathrm{~b}$ & $0.26 \mathrm{c}$ & \\
\hline
\end{tabular}

${ }^{v}$ Mean infection severity (number of lesions per $\mathrm{cm}^{2}$ of leaf area) of three replications in time. Plants were exposed to the temperature regime for $24 \mathrm{~h}$ and then placed at $18^{\circ} \mathrm{C}$ for 9 days.

wPlants were inoculated with conidial suspension and air-dried prior to exposure to each temperature regime.

x Growth chambers were programmed for a constant $18^{\circ} \mathrm{C}$ or averaged temperature data from 13 hop yards in the Yakima Valley, WA, for 8 May 2000 and 9 August 2000. These days were randomly chosen from their respective months. The temperature regime is shown in Figure 1A.

${ }^{y}$ Mean infection severity at said inoculation time across all temperature regimes. Means in this column followed by the same letter are not significantly different at $P=0.05$ (Fisher's protected least significant difference test).

${ }^{\mathrm{z}}$ Mean infection severity at said temperature regime across all inoculation times. Means in this row followed by the same letter are not significantly different at $P=0.05$ (Fisher's protected least significant difference test). borne conidia postinoculation. Ypema and Gubler (29) indirectly examined the prolonged effect of fluctuating temperature on the infection severity of Erysiphe necator (formerly Uncinula necator) on grape by observing conidia production from plants exposed to various temperature regimes for 53 days. Exposure of infected plants to temperature regimes of $36^{\circ} \mathrm{C}$ for $6 \mathrm{~h}$ and $40^{\circ} \mathrm{C}$ for $3 \mathrm{~h}$ resulted in no detectable sporulation within 23 days after beginning the temperature treatments. They concluded that the loss of sporulation was most likely because of impaired infection, which agrees with the data presented here.

The time of inoculation or spore deposition onto leaves had a significant effect on disease development under simulated field temperatures. Significantly greater disease severity following inoculation at 1700 or $2100 \mathrm{~h}$ is most likely because of the short duration or absence of exposure to supraconducive temperatures prior to exposure to conducive temperatures. It is not clear why time of inoculation would have a significant impact on infection severity of plants maintained at a constant $18^{\circ} \mathrm{C}$. It is possible that the differences in infection severity at $1300 \mathrm{~h}$ are a result of the lower humidity at this time; however, similar humidity levels were also recorded at $1700 \mathrm{~h}$, with a low occurring around $1600 \mathrm{~h}$ (data not shown). Numerous studies have shown a reduction in germination and germ tube elongation of powdery mildew fungi on glass slides associated with decreases in relative humidity $(8,16)$. However, when detached leaves were also examined, there are conflicting results regarding the effects of humidity on germination $(17,19,27)$. This could be related to the effects of transpiration. When intact plants were used, there was little effect on germination associated with decreases in relative humidity $(4,28)$. Manners and Hossain (11) observed for Blumeria graminis f. sp. avenae, hordei, and tritici that, the further relative humidity di-

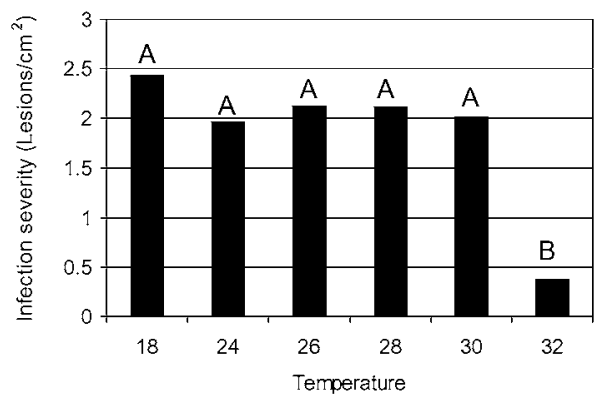

Fig. 4. Effect of temperature on leaf susceptibility of hops to infection by Podosphaera macularis. All plants were grown at their respective temperature for 7 days prior to inoculation with a conidial suspension, air-dried, and then placed at $18^{\circ} \mathrm{C}$ for 10 days. Means followed by the same letter are not significantly different at $P=0.05$ using Fisher's protected least significant difference test.

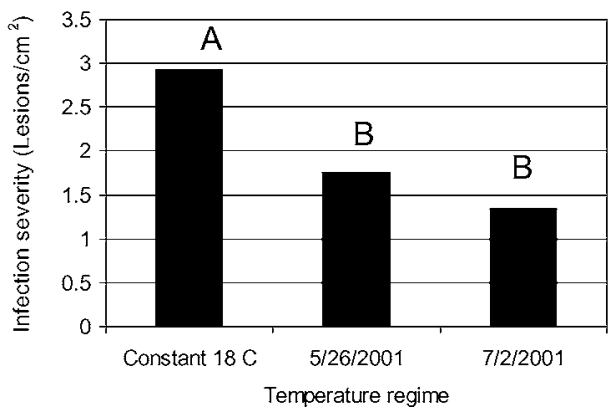

Fig. 5. Effect of simulated field temperatures on leaf susceptibility of hops to infection by Podosphaera macularis. All plants were grown at their respective temperature regime (Fig. 1B) for 7 days prior to inoculation with a conidial suspension, air-dried, and then placed at $18^{\circ} \mathrm{C}$ for 10 days. Means followed by the same letter are not significantly different at $P=0.05 \mathrm{using}$ Fisher's protected least significant difference test. 
verged from the optimal, the greater the effect of supraconducive temperatures. A humidity $\times$ temperature interaction does not explain why the same effect of inoculation time was observed when only the constant $18^{\circ} \mathrm{C}$ treatment was analyzed. The most probable explanation is that this phenomenon is due to leaf surface temperatures being greater than the ambient air because of effects of light irradiation. Burrage (2) observed temperatures on exposed hop leaves 3.4 to $5.6^{\circ} \mathrm{C}$ greater than ambient air and $2.5^{\circ} \mathrm{C}$ lower in shaded areas. It is possible that light levels were great enough in the simulated field temperature experiments to cause increased heat gain on the leaf surface, thus increasing the exposure temperature.

The effects of temperature on leaf susceptibility to $P$. macularis could be related to changes in the cuticle and epidermal cell walls under low-humidity and high-temperature conditions $(9,10,12,13$, 21). The increased thickness could act as a physical barrier to penetration. Jhooty and McKeen (8) observed that $P$. macularis infection of strawberry was related to a combination of cuticle and cell wall thickness, while Peries (17) attributed resistance among strawberry varieties to the quantity of cutin in the cuticle. Under conditions of high humidity or low temperature, hop leaves remain succulent longer than those exposed to low humidity, high temperature, or both (W. F. Mahaffee, personal observation). Exposure of $H$. lupulus to temperatures $>33^{\circ} \mathrm{C}$ resulted in more brittle leaves than those on plants grown at 30 or $18^{\circ} \mathrm{C}$. Similarly, foliar applications of copper have been shown to decrease susceptibility of $H$. lupulus to P. macularis (20). These applications are thought to increase epidermal cell wall thickness (1) and sugar content of epidermal cells (7).

The data presented here indicate that any disease-forecasting system for hop powdery mildew, and probably for other powdery mildews, should have rules addressing the effect of supraconducive temperatures on infection and plant susceptibility, in addition to accounting for the periods conducive for infection. The effects of these periods need to be assessed based on when they occur in relation to each other and when conidia are being dispersed and deposited onto leaf surfaces. It also appears that knowledge of how the plant responds to temperature is needed to further enhance disease forecasting of powdery mildews.

\section{ACKNOWLEDGMENTS}

We acknowledge funding from the Hop Research Council, Washington Commission on Pesticide Registration, Washington Hop Commission, Western Farm Services, and Wilbur-Ellis. We thank I. Cantrell, C. Soskis, and A. Taylor for technical assistance. We thank the two anonymous reviewers for the helpful suggestions to improve the manuscript.

\section{LITERATURE CITED}

1. Barner, V. J., and Röder, K. 1964. Die Einwirkung von Fungiziden auf die Ausbildung des Blattdeckgewebes und das Verhüten einiger Pflanzenparasiten. Z. Pflanzenkrankh. Pflanzenschutz 71:210-215.

2. Burrage, S. W. 1971. The micro-climate at the leaf surface. Pages 91-101 in: Ecology of Leaf Surface Micro-organisms. T. F. Preece and C. H. Dickson, Eds. Academic Press, New York.

3. Chellemi, D. O., and Marois, J. J. 1991. Sporulation of Uncinula necator on grape leaves as influenced by temperature and cultivar. Phytopathology $81: 197-201$.
4. Delp, C. J. 1954. Effect of temperature and humidity on the grape powdery mildew fungus. Phytopathology 44:615-626.

5. Gomez, K. A., and Gomez, A. A. 1984. Statistical Procedures for Agricultural Research. John Wiley \& Sons, New York.

6. Haunold, A., and Zimmermann, C. E. 1974. Pollen collection, crossing, and seed germination of hop. Crop Sci. 14:774-776.

7. Horsfall, J. G., and Dimond, A. E. 1957. Interactions of tissue sugar, growth substances, and disease susceptibility. Z. Pflanzenkrankh. Pflanzenschutz 64:415-421.

8. Jhooty, J. S., and McKeen, W. E. 1965. Studies on powdery mildew of strawberry caused by Sphaerotheca macularis. Phytopathology 55:281285.

9. Juniper, B. E. 1960. Growth, development, and effect of the environment on the ultra-structure of plant surfaces. J. Linn. Soc. Lond. Bot. 56:413419.

10. Lee, B., and Priestley, J. H. 1924. The plant cuticle. Ann. Bot. (Lond.) 38:524-545.

11. Manners, J. G., and Hossain, S. M. M. 1963. Effects of temperature and humidity on conidial germination in Erysiphe graminis. Trans. Brit. Mycol. Soc. 46:225-234.

12. Martin, J. T. 1964. Role of cuticle in the defense against plant disease. Annu. Rev. Phytopathol. 26:81-100.

13. Martin, J. T., and Juniper, B. E. 1970. The Cuticles of Plants. St. Martin's Press, New York.

14. Neve, R. A. 1991. Hops. Chapman and Hall, New York.

15. Ocamb, C. M., Klein, R., Barbour, J., Griesbach, J., and Mahaffee, W. 1999. First report of hop powdery mildew in the Pacific Northwest. Plant Dis. 83:1072.

16. Oku, H., Hatamoto, S. O., and Fujii, S. 1975. Effect of temperature and humidity on the development of powdery mildew of grape. Sci. Rep. Fac. Agric. Okayama Univ. 45:16-20.

17. Peries, O. S. 1962. Studies on strawberry mildew, caused by Sphaerotheca macularis (Wallr. ex Fries) Jaczewski. Ann. Appl. Biol. 50:211-224.

18. Price, T. V. 1970. Epidemiology and control of powdery mildew (Sphaerotheca pannose) on roses. Ann. Appl. Biol. 65:231-248.

19. Quinn, J. A., and Powell, C. C., Jr. 1982. Effects of temperature, light, and relative humidity on powdery mildew of begonia. Phytopathology $72: 480-484$

20. Royle, D. J., and Griffin, M. J. 1973. Side-effects of downy mildew fungicides on the incidence of hop powdery mildew (Sphaerotheca humuli). Plant Pathol. 22:129-133.

21. Skoss, J. D. 1955. Structure and composition of plant cuticle in relation to environmental factors and permeability. Bot. Gaz. 117:55-72.

22. Turechek, W. W., Mahaffee, W. F., and Ocamb, C. M. 2001. Development of management strategies for hop powdery mildew in the Pacific Northwest. Online. Plant Health Progress doi:10.1094/PHP-2001-031301-RS.

23. Xu, X.-M. 1999. Effects of temperature on the latent period of the rose powdery mildew pathogen, Sphaerotheca pannosa. Plant Pathol. 48:662667.

24. Xu, X.-M., and Butt, D. J. 1998. Effects of temperature and atmospheric moisture on the early growth of apple powdery mildew (Podosphaera leucotricha) colonies. Eur. J. Plant Pathol. 104:133-140.

25. Xu, X.-M., and Robinson, J. D. 2000. Effects of temperature on the incubation and latent periods of hawthorn powdery mildew (Podosphaera clandestina). Plant Pathol. 49:791-797.

26. Xu, X., and Robinson, J. 2001. The effects of temperature on the incubation and latent periods of powdery mildew (Erysiphe polygoni) on clematis. J. Phytopathol. 149:565-568.

27. Yarwood, C. E. 1936. The tolerance of Erysiphe polygoni and certain other powdery mildews to low humidity. Phytopathology 26:845-859.

28. Yarwood, C. E. 1957. Powdery mildews. Pages 235-301 in: The Botanical Review. E. H. Fulling, Ed. The New York Botanical Gardens, New York.

29. Ypema, H. L., and Gubler, W. D. 1997. Long-term effect of temperature and triadimefon on proliferation of Uncinula necator: Implications for fungicide resistance and disease risk assessment. Plant Dis. 81:1187-1192. 